\title{
Morphological Transformation and Estimation of Normal Growth Curve of Both Morphological Forms of Sporothrix schenckii
}

\author{
Rajesh Kumar Shah ${ }^{1 *}$, Hemant B. Gadekar ${ }^{1}$, Vikas Jain ${ }^{1}$, Sweta Kumari ${ }^{2}$, \\ Apoorva Tripathi ${ }^{1}$, Sanjo Gupta ${ }^{1}$ and Neelam ${ }^{1}$ \\ ${ }^{1}$ Department of Microbiology, ${ }^{2}$ Department of Physiology, RKDFMCH\&RC Bhopal- 462026, \\ $M P$, India \\ *Corresponding author
}

\section{A B S T R A C T}

Keywords

Morphlogical,

Transformation,

Sporothrix schenckii,

Optical density, Normal growth curve

\section{Article Info}

Accepted:

10 October 2018

Available Online:

10 November 2018
Morphological transformation of pathogenic fungi is an important factor contributing in pathogenicity. Sporothrix schenckii is a dimorphic fungus, capable of transforming from filamentous form to yeast form in presence of nutritional factors and environmental conditions. This is very much essential for identification to establish definitive diagnosis of sporotrichosis in-vitro. A six times repeated successive subculture of a standard filamentous S. schenckii (MTCC1359) was done on Brain heart infusion blood agar (BHIBA) incubated at $37^{\circ} \mathrm{C}$ in presence of $5-10 \% \mathrm{CO}_{2}$ and humidity to transform yeast form. A normal growth curve of both yeast and filamentous stage of S. schenckii were plotted by recording every day optical densities (ODs) of broth culture in yeast nitrogen base (YNB) media at $540 \mathrm{~nm}$ of wavelength in colorimeter. By observing the graphs of yeast and mould form, the $\log$ phase were from $2^{\text {nd }}$ to $14^{\text {th }}$ day and $3^{\text {rd }}$ to $18^{\text {th }}$ day, stationary phase $14^{\text {th }}$ to $20^{\text {th }}$ day and $18^{\text {th }}$ to $21^{\text {st }}$ day, death phase $20^{\text {th }}-33^{\text {rd }}$ day and $21^{\text {st }}-$ $33^{\text {rd }}$ day respectively. It is necessary to know the normal growth curve of fungus for various further scientific studies which is not standardized yet like standardized bacterial normal growth curve.

\section{Introduction}

Sporothrix schenckii, a dimorphic fungus and is an etiological agent of sporotrichosis. The disease is acquired by prick of thorn and in the tissue, fungus differentiates into yeast form (Chander, 2002). The disease starts to disseminated mycosis in immune compromised patient and can be life threatening and difficult to treat (Barrows et al., 2011). The fungus lives its filamentous saprophytic life in soil and at room temperature i.e., $25^{\circ} \mathrm{C}$, but in animal tissue as a budding yeast cell (Toledo et al., 2000). Therefore, it is important to study in-vitro morphological transformation of S. schenckii to yeast form. For which along with temperature $\mathrm{CO}_{2}$ concentration and nutritional factors are also the key contributors to transform mould to yeast form (Caban et al., 2011).

When a standardize inoculums of both mycelia and yeast form of S. schenckii are 
inoculated into broth culture media. The cells begin to prepare for its replication by preparing DNA and a cellular enzyme required in their replication known as lag phase (Bareja et al., 2015). After synthesis of the macromolecules, A phase of exponential or logarithmic follows where biomass of the cells increases linearly with time by doubling cells count with every unit of time. When the stationary phase is reached, there is no longer a net increase in viable cell number and decrease in cellular metabolic activity, where the growth rate is equal to death rate. Cellular growth is inhibited during the stationary phase because of depletion of the essential nutrients and accumulation of metabolic inhibitory byproducts. Eventually, death phase is reached where cells are lysed due to the accumulation of inhibitory toxic products, depletion of cellular energy (Qadiri et al., 2008).

There is a dearth of study on morphological transformation and their normal growth curve estimation. Hence, it was decided to know morphological transformation of mould to yeast form of S. schenckii and to estimate their normal growth curve by using enriched media and estimating their turbidity.

\section{Materials and Methods}

The study was conducted at the department of Microbiology in a tertiary care hospital of Central India. A standard strain of S. schenckii MTCC 1359 (mould form) was used in this study. Morphological transformation of mould to yeast form in S. schenckii was attained by repeated sub-culture of mycelia or conidia on enriched culture medium, Brain heart infusion blood agar (BHIBA) and incubated $37^{\circ} \mathrm{C}$ for 5-7 days in presence of 5-10\% $\mathrm{CO}_{2}$. A times Six successive subcultures were done to obtain yeast form of S. schenckii (Garrison et al., 1975). The growth was confirmed by colony characteristics and microscopic examination (Fisher and Cook, 1998). Yeast nitrogen base medium (YNB) was used for further growth character of $S$. schenckii. The YNB was prepared and distributed in $5.0 \mathrm{~mL}$ aliquots in test tubes and were sterilized and refrigerated for further studies. Growth of S. schenckii yeast (from slope of BHI BA) and mould (From SDA) were sub-cultured in $5.0 \mathrm{~mL}$ of YNB medium in test tubes and incubated at $37^{\circ} \mathrm{C}$ and $25^{\circ} \mathrm{C}$ respectively. On the seventh day $0.1 \mathrm{~mL}$ of both the yeast and mould suspension in test tubes were sub-cultured into $5.0 \mathrm{~mL}$ of YNB medium in two tubes separately for yeast and mould form and the suspensions were standardized by adjusting $90 \%$ transmittance at $540 \mathrm{~nm}$ in a colorimeter. After that, their optical densities (ODs) were recorded and then tubes were reincubated at $37^{\circ} \mathrm{C}$ and $25^{\circ} \mathrm{C}$ respectively for yeast and mould forms. Thereafter, daily readings of ODs for both morphological forms were taken to obtain a growth curve.

\section{Results and Discussion}

With a repeated subcultures of a standard strain of S. Schenckii (mycelia form) on BHIBA, a creamy white, beige or tan coloured smooth colonies appeared after a six successive repeated subcultures. The yeast forms of transformed colonies were further confirmed macroscopically by observing typical colony morphology and microscopically with gram staining.

The normal growth curves of both morphological forms of $S$. schenckii were estimated by taking every day ODs at $540 \mathrm{~nm}$ of wavelength on a colorimeter till $34^{\text {th }}$ days. The graphs for normal growth curves of both morphological forms plotted by taking ODs on $\mathrm{Y}$-axis and days on $\mathrm{X}$-axis.

In yeast form of S.schenckii, It is clear from the graph that the lag phase is of $48 \mathrm{hrs}$. Thereafter a steadily rising rate of growth which lasts from $48 \mathrm{hrs}$ to $14^{\text {th }}$ days is $\log$ 
phase followed with stationary phase from $14^{\text {th }}$ to $20^{\text {th }}$ days and decline phase starting from $20^{\text {th }}$ to $33^{\text {rd }}$ days. Similarly by observing mould form of $S$. schenckii, it is clear that the lag phase is of $72 \mathrm{hrs}$ ( $3^{\text {rd }}$ day). Thereafter a steadily rising rate of growth which lasts from $3^{\text {rd }}$ to $18^{\text {th }}$ days is $\log$ phase followed with stationary phase from $18^{\text {th }}$ to $21^{\text {st }}$ days and decline phase starting from $21^{\text {st }}$ to $33^{\text {rd }}$ days.

It is essential to demonstrate transformation of mould to yeast form in all the isolates of pathogenic and non-pathogenic species of S.schenckii and vice versa. It requires three important essential factors which are very much necessary for transformation of dimorphic fungi like $S$. schenckii, i.e., temperature, enriched media containing amino acids and vitamins, humid environment with 5-10\% $\mathrm{CO}_{2}$ (Fisher and Cook, 1998).

Barrows et al., (2011) mentioned that for the identification of an isolate as $S$. schenckii, one must demonstrate that it undergoes dimorphism by sub culturing the fungus on enriched media such as brain heart infusion agar, chocolate agar, and blood agar at 35 to $37^{\circ} \mathrm{C}$ for 5 to 7 days. Occasional isolates can be difficult to convert and may require multiple subcultures and extended incubation. Criseo et al., (2008) converted mould form of $S$. schenckii to yeast form by repeated subculture onto the Brain heart infusion agar (BHI agar) at $37^{\circ} \mathrm{C}$. During their study of the environmental distribution of S. schenckii in Calabria and Sicily in southern Italy, the clinical isolate had been subcultured several times and used as a standard strain in both phenotypic and molecular experiments. Interestingly, the mycelial growth of this clinical strain changed and a permanent yeastlike form was isolated from cultures of $S$. schenckii. The yeast-like strain, named Spy1, was found to grow permanently in the yeast phase and was not influenced by temperature. In fact, this strain grew well on Sabouraud dextrose agar (SDA) at 24, 28, 30, 34, and $37^{\circ} \mathrm{C}$, respectively. The growth rate of the Spy1 strain was higher than that of the wildtype strain as well (Criseo et al., 2008) (Fig. $1-4$; Table 1 and 2).

Fig.1 Six times repeated successive subculture of S. schenckii on BHIBA to transform mould to yeast form

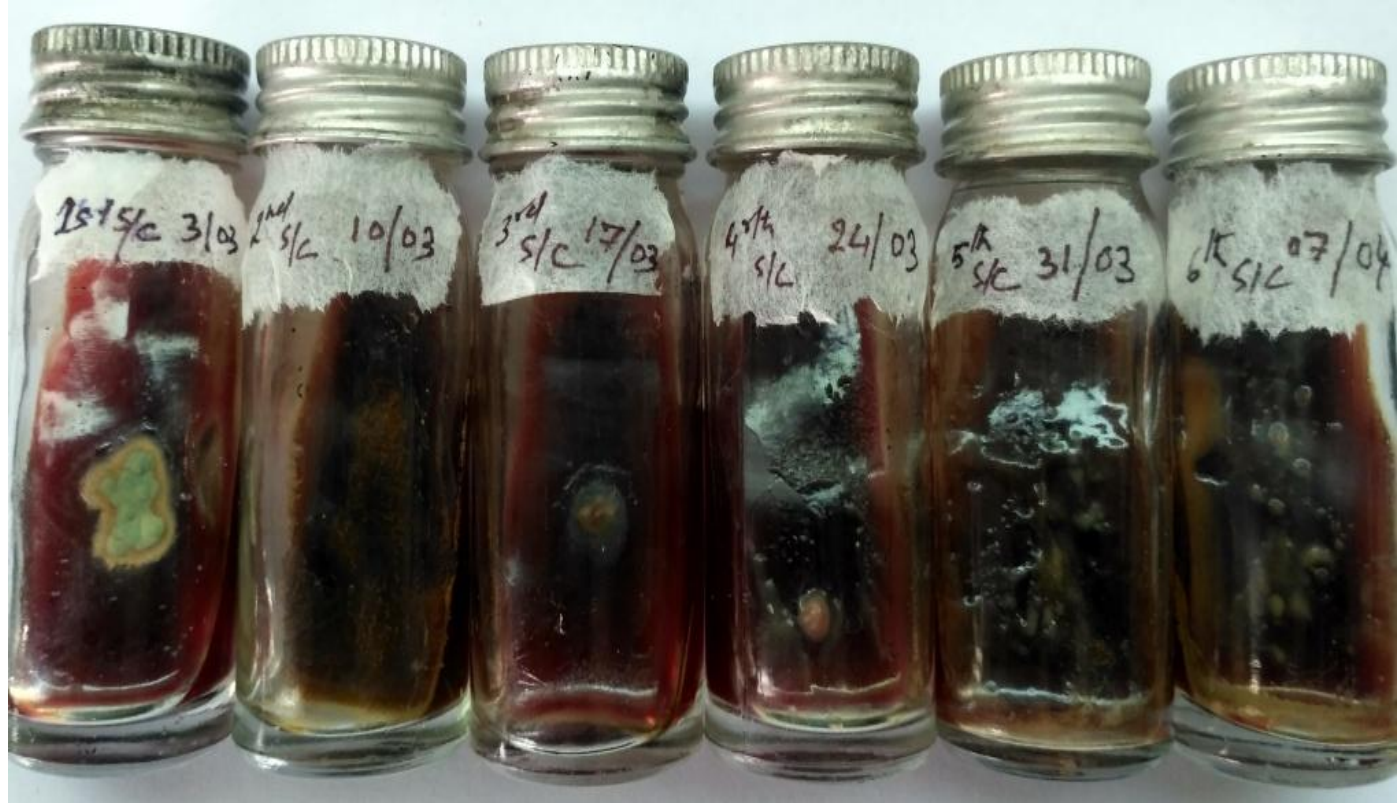


Fig.2 Gram stained smears showing gradual transformation from mould to yeast form of S. schenckii

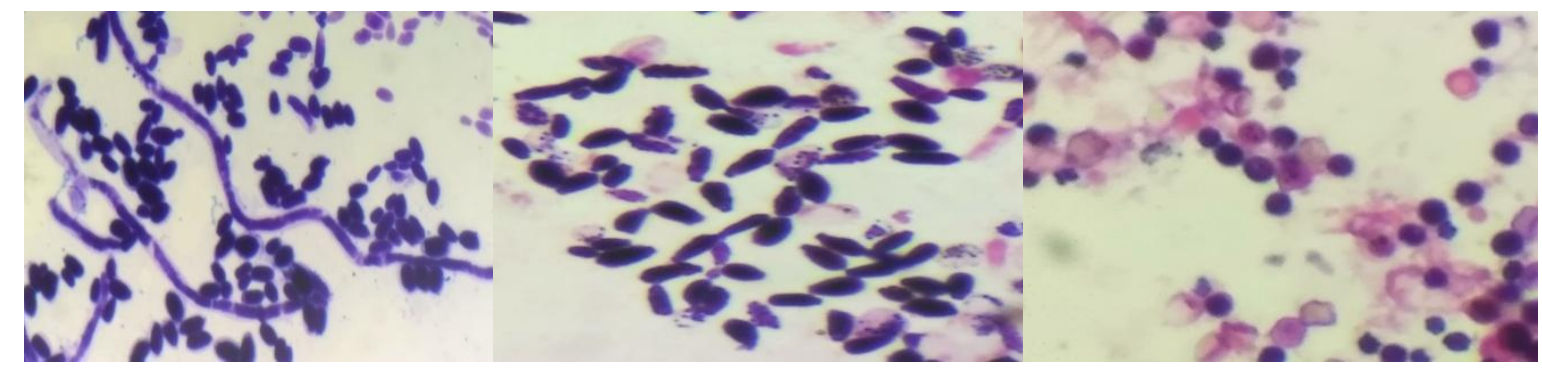

Fig.3 Normal growth curve of yeast form of S. schenckii obtained

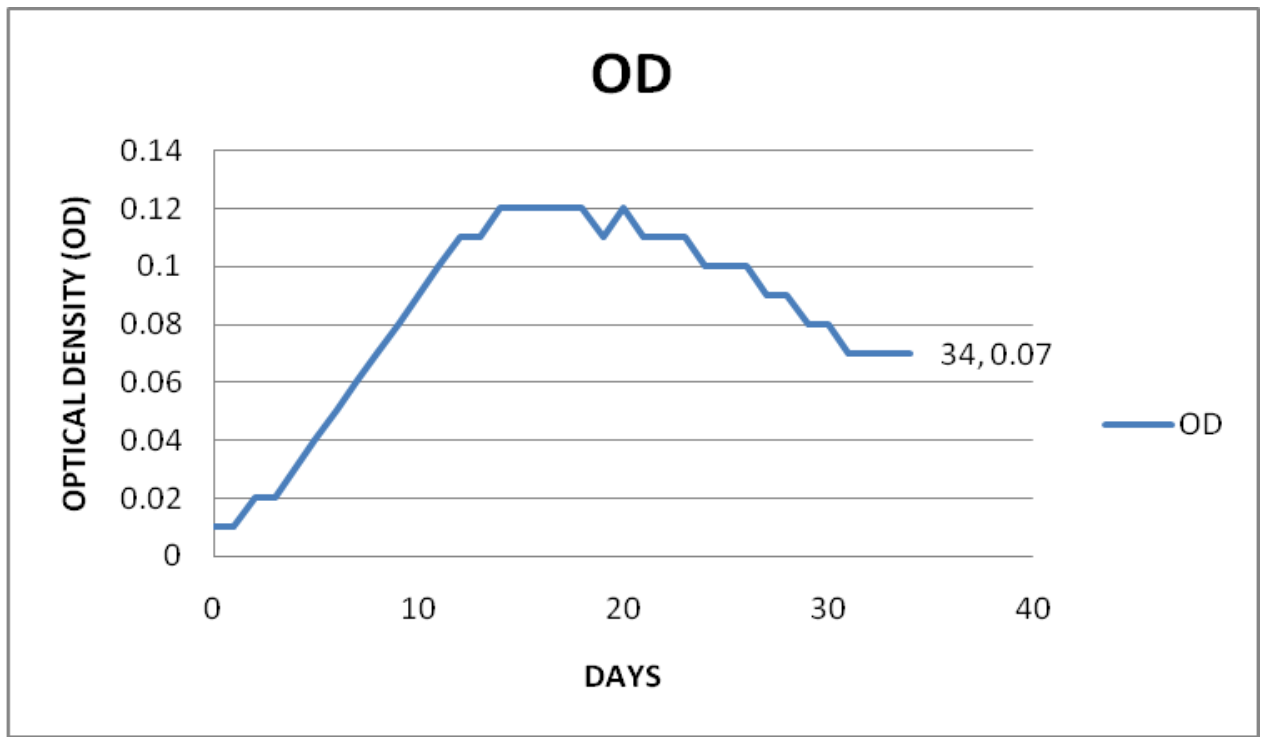

Fig.4 Normal growth curve of mould form of S. schenckii obtained




Table.1 Optical densities of yeast form of S. schenckii on different days

\begin{tabular}{|c|c|c|c|}
\hline DAYS & OD & DAYS & OD \\
\hline $\mathbf{0}$ & 0.01 & 18 & 0.12 \\
\hline $\mathbf{1}$ & 0.01 & 19 & 0.11 \\
\hline $\mathbf{2}$ & 0.02 & 20 & 0.12 \\
\hline $\mathbf{3}$ & 0.02 & 21 & 0.11 \\
\hline $\mathbf{4}$ & 0.03 & 22 & 0.11 \\
\hline $\mathbf{5}$ & 0.04 & 23 & 0.11 \\
\hline $\mathbf{6}$ & 0.05 & 24 & 0.1 \\
\hline $\mathbf{7}$ & 0.06 & 25 & 0.1 \\
\hline $\mathbf{8}$ & 0.07 & 26 & 0.1 \\
\hline $\mathbf{9}$ & 0.08 & 27 & 0.09 \\
\hline $\mathbf{1 0}$ & 0.09 & 28 & 0.09 \\
\hline $\mathbf{1 1}$ & 0.1 & 29 & 0.08 \\
\hline $\mathbf{1 2}$ & 0.11 & 30 & 0.08 \\
\hline $\mathbf{1 3}$ & 0.11 & 31 & 0.07 \\
\hline $\mathbf{1 4}$ & 0.12 & 32 & 0.07 \\
\hline $\mathbf{1 5}$ & 0.12 & 33 & 0.07 \\
\hline $\mathbf{1 6}$ & 0.12 & 34 & 0.07 \\
\hline $\mathbf{1 7}$ & 0.12 & & \\
\hline
\end{tabular}

Table.2 Optical densities of mould form of $S$. schenckii on different days

\begin{tabular}{|l|l|l|l|}
\hline DAYS & OD & DAYS & OD \\
\hline 0 & 0.01 & 18 & 0.26 \\
\hline $\mathbf{1}$ & 0.01 & 19 & 0.26 \\
\hline $\mathbf{2}$ & 0.01 & 20 & 0.26 \\
\hline $\mathbf{3}$ & 0.03 & 21 & 0.26 \\
\hline $\mathbf{4}$ & 0.04 & 22 & 0.25 \\
\hline $\mathbf{5}$ & 0.06 & 23 & 0.24 \\
\hline $\mathbf{6}$ & 0.09 & 24 & 0.23 \\
\hline $\mathbf{7}$ & 0.1 & 25 & 0.22 \\
\hline $\mathbf{8}$ & 0.12 & 26 & 0.22 \\
\hline $\mathbf{9}$ & 0.15 & 27 & 0.21 \\
\hline $\mathbf{1 0}$ & 0.18 & 28 & 0.21 \\
\hline $\mathbf{1 1}$ & 0.19 & 29 & 0.2 \\
\hline $\mathbf{1 2}$ & 0.21 & 30 & 0.19 \\
\hline $\mathbf{1 3}$ & 0.22 & 31 & 0.19 \\
\hline $\mathbf{1 4}$ & 0.22 & 32 & 0.18 \\
\hline $\mathbf{1 5}$ & 0.23 & 33 & 0.17 \\
\hline $\mathbf{1 6}$ & 0.24 & 34 & 0.17 \\
\hline $\mathbf{1 7}$ & 0.25 & & \\
\hline
\end{tabular}


Garrison et al., (1975) reported that for transformation of mycelia form to yeast form, the fungal hyphal elements separated and inoculated on BHI broth and incubated it at $37^{\circ} \mathrm{C}$ for four days to study the changes in ultra-structure of $S$. schenkii during its transformation to yeast form (Garrison et al., 1975).

In this study, we used turbidometric method to obtain ODs of the $S$. schenckii (yeast and mould form) grown in YNB medium incubated at by $37^{\circ} \mathrm{C}$ and $25^{\circ} \mathrm{C}$ respectively. Thereafter, everyday ODs taken till 34 days and normal growth curve plotted for both yeast and mould morphological forms showing lag phase of $48 \mathrm{hrs}$ (yeast) and $72 \mathrm{hrs}$ (mould), log phase (exponential phase) i.e., 48 hrs-14 days (yeast) and 72 hrs-18 days (mould), stationary phase (14-20 days (yeast) and 18-21 days (mould) and death phase 2033 days (yeast) and 21-33 days (mould). The normal growth curve so obtained for yeast and mould form of $S$. schenckii is very much similar to bacterial growth curve mentioned by Atlas (1988). During the lag phase, cells show no growth although cells increase in size but begin to prepare for reproduction such synthesis of DNA and cellular enzymes mentioned by Qadiri et al., (2008). Akerlund et al., (1995) demonstrated the increase of cellular biomass during the log phase linearly with time, with the number of cells doubling with every unit of time. This phase is defined as the balanced growth stage because the average composition of the cells remains constant with culture properties (i.e., protein and DNA) increasing at the same rate. When the stationary phase is reached, there is no longer a net increase in viable cells number and cellular metabolic activity is decreased which means the growth rate is equal to the death rate (Akerlund et al., 1995). During the transition between log and stationary phase, cellular components are synthesized at unequal rates (unbalanced growth); therefore, the biochemical composition of cells in the stationary phase is different from that in the log phase (Atlas, 1988). Cellular growth is inhibited during the stationary phase since the essential nutrients required for their growth are exhausted and metabolic inhibitory byproducts accumulate. Eventually, death phase is reached where cells are broken down (cells lyses) due to the additional accumulation of inhibitory by products, depletion of cellular energy, and pH changes (Qadiri et al., 2008).

In this study, it took six weeks of repeated successive subcultures of $S$. schenckii on BHIBA in presence of $5-10 \% \quad \mathrm{CO}_{2}$ and humidity to transform from mould to yeast form. For the estimation of normal growth curves of yeast and mould forms, standardized inoculums were prepared calorimetrically and inoculated into $\mathrm{YNB}$ medium then incubated at $37^{\circ} \mathrm{C}$ and $25^{\circ} \mathrm{C}$ for 34 days respectively. Thereafter, a normal growth curve for yeast and mould form obtained with every days readings of their ODs. The estimated normal growth curve of yeast form showed a lag phase of 2 days, log phase of 12 days, stationary phase of 7 days and decline phase of 10 days. For mould form, the estimated normal growth curve showed a lag phase of 3 days, log phase of 15 days, stationary phase of 4 days and decline phase of 11 days.

\section{References}

Akerlund, T., Nordstrom, K., and Bernander, R. 1995. Analysis of cell size and DNA content in exponentially growing and stationary phase batch cultures of Escherichia coli. J. Bacteriol; 177: 6791-6797.

Atlas, R.M. 1988. Microbiology fundamentals and applications. Macmillan publishing company, Ney York. $2^{\text {nd }}$ edition. Pp.106110. 
Bareja, R., Grover, P.S. and Mehra, S.K. 2015. Determination of growth curve of Sporothrixs chenckii in mycelial phase. IORS JDMS; 14 (4):121-123.

Barrows, M.B.L., Paes, R.A. and Schubach, A.O. 2011. Sporothrix schenckii and sporotrichosis. Clin Microbiol Rev; 24(4):633-654.

Caban, J.R., Velazquez, W.G., Sanchez, L.P., Mendez R.G and Valle, N.R. 2011. Calcium/calmdulinkinase 1 and its relation to thermotolerance and HSP90 in Sporothrix schenckii: an RNAi and yeast two hybrid study. BMC microbial; 11(162): 1-16.

Chander, J. Textbook of Medical Mycology. Mehta publisher. 2002; second edition: 128-137.

Criseo, G., Zungri, D. and Romeo, O. 2008. Stable yeast like form of Sporothrix schenckii: lack of dimorphic stage. J. Clin. Microbiol., 46(11): 3870-3871.

Fisher, F. and Cook, N.B. 1998. Fundamentals of Diagnostic Mycology. Saunders, the Curtiscenter,
Independence square west, Philadelphia. Pp.182-185.

Garrison, R.G., Boyd, K.S. and Marial, F.1975. Ultrastructural studies of mycelium to yeast transformation of $S$. schenckii. J. bacterial; 124(2): 959-968.

Garrison, R.G., Boyd. K.S. and Mariat, F. 1975. Ultrastructural studies of the mycelium to yeast transformation of Sporothrix schenckii. Journal of Bacteriology; 124(2): 959-968.

Qadiri, H.M., Alami, N.A., Lin, M., Holy, M.A., Cavinato, A.G. and Rasco, B.A. 2008. Studying of the bacterial growth phases using Fourier transform infrared spectroscopy and multivariate analysis. $J$. rapid method \& automaton in micrbiol; 16: 73-89.

Toledo, M.S., Lovery S.B., Straus, A.H. and Takahashi, H.K. 2000. Dimorphic expression of cerebrosides in mycopathogen Sporothrixschenckii. J. Lipid Research; 41: 797-806.

\section{How to cite this article:}

Rajesh Kumar Shah, Hemant B. Gadekar, Vikas Jain, Sweta Kumari, Apoorva Tripathi, Sanjo Gupta and Neelam. 2018. Morphological Transformation and Estimation of Normal Growth Curve of Both Morphological Forms of Sporothrix schenckii. Int.J.Curr.Microbiol.App.Sci. 7(11): 1078-1084. doi: https://doi.org/10.20546/ijcmas.2018.711.125 